\title{
Percutaneous Reversal of Cyanosis on Catheterization Table in a 12-Year-Old Boy using Cera Vascular Plug - A Case Report
}

\author{
Santosh Kumar Sinha, FACC, FAESC, FSCAI (D), Mahmodullah Razi, Umeshwar Pandey \\ and Vinay Krishna
}

Department of Cardiology, LPS Institute of Cardiology, GSVM Medical College, India

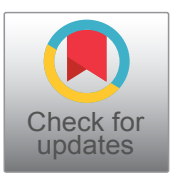

*Corresponding author: Santosh Kumar Sinha, FACC, FAESC, FSCAI, Associate Professor, Department of Cardiology, LPS Institute of Cardiology, GSVM Medical College, Kanpur, Uttar Pradesh, 208002, India, Tel: +91-9670220088, Fax: +910512-2556199; 2556521

\begin{abstract}
Pulmonary arteriovenous malformations are commonly treated by embolization with coils or balloons to prevent cerebral complications and to raise the oxygenation of the blood. The Cera vascular plug (Lifetech Scientific, Shenzhen, China) is a new vascular device made of a self-expanding cylindrical nitinol mesh. Here we report a case of a 13-year-old boy who had presented with 4 year history of progressive exertional dyspnoea, cyanosis, and clubbing. Pulmonary arterio-venous malformation (multiple) was diagnosed which was arising from right pulmonary artery. Complete occlusion was achieved using two $12 \mathrm{~mm}$ Cera vascular plug, thereby reversing the cyanosis on catheterization table. On follow up at 9 months, clubbing also disappeared.
\end{abstract}

\section{Keywords}

Pulmonary arteriovenous malformations, Cera vascular plug, Cyanosis, Clubbing

\section{Introduction}

Pulmonary arteriovenous malformations (PAVM) are abnormal communications between the pulmonary arteries and veins without any intervening capillary beds. Most of them are syndromic (70-95\%), seen in association with hereditary hemorrhagic telangiectasia (Osler-Weber Rendu-syndrome), characterized by recurrent epistaxis, mucocutaneous telangiectasia and visceral vascular involvement $[1,2]$. The sporadic types of PAVM are rare arteriovenous communications that may develop in virtually any organ and especially in the lungs. These may complicate into cyanosis, dyspnoea, massive haemoptysis, haemothorax, as well as neuro- logic complications, including transient ischemic attack, cerebral stroke and cerebral abscess due to the right-toleft shunting that facilitates the passage of septic emboli into the cerebral circulation [1]. Thus these warrant treatment treating even for asymptomatic one if technically feasible. These can be treated percutaneously by transcatheter embolization, using detachable balloons, coils, and vascular plugs [3]. Most of their closure have been reported using Amplatzer vascular plug [4,5]. Cera vascular plug (Lifetech Scientific, Shenzhen, China) is a relatively new device which has been used quite recently in few cases for arterial and venous embolization [6]. Simple investigation like contrast echocardiogram using agitated saline can be used to conclusively identify pulmonary AVMs. When treating pulmonary AVMs, embolization with arterio-venous plug (AVP) is a less time consuming and safe method [7].

\section{Case Report}

A 13-year-old boy presented with 4 years history of progressive exertional dyspnoea. There was no history of squatting, cyanotic spells, recurrent lower respiratory tract infection, epistaxis and bleeding per rectum. There was no family history of bleeding disorders. Clinical examination showed central cyanosis (oxygen saturation$89 \%)$, pan-digital clubbing, normal heart sounds and silent precordium. There was a short systolic bruit audible in right infra axillary area which was getting intensified with deep inspiration. Electrocardiogram was normal. Chest X-ray showed a homogenous opacity in the right

Citation: Sinha SK, Razi M, Pandey U, Krishna V (2020) Percutaneous Reversal of Cyanosis on Catheterization Table in a 12-Year-Old Boy using Cera Vascular Plug - A Case Report. Int J Clin Cardiol 7:192. doi.org/10.23937/2378-2951/1410192

Accepted: July 27, 2020; Published: July 29, 2020

Copyright: (C) 2020 Sinha SK, et al. This is an open-access article distributed under the terms of the Creative Commons Attribution License, which permits unrestricted use, distribution, and reproduction in any medium, provided the original author and source are credited. 
lower zone (Figure 1). Trans-thoracic echocardiogram was otherwise normal. Contrast echocardiogram revealed dense opacification of left atrium and consequently left ventricle after 4 cardiac cycles following appearance of contrast in the right heart chambers on administering agitated saline contrast. Based on above findings, it was diagnosed as sporadic pulmonary AVM. Cardiac catheterization was done using 6F multipurpose catheter (MP) which was advanced into right pulmonary artery (RPA) showing two arterio-venous fistula which had restrictive diameter of $8.5 \mathrm{~mm}$ along the length of AVM (Figure 2).

Percutaneous device closure of AVM was planned

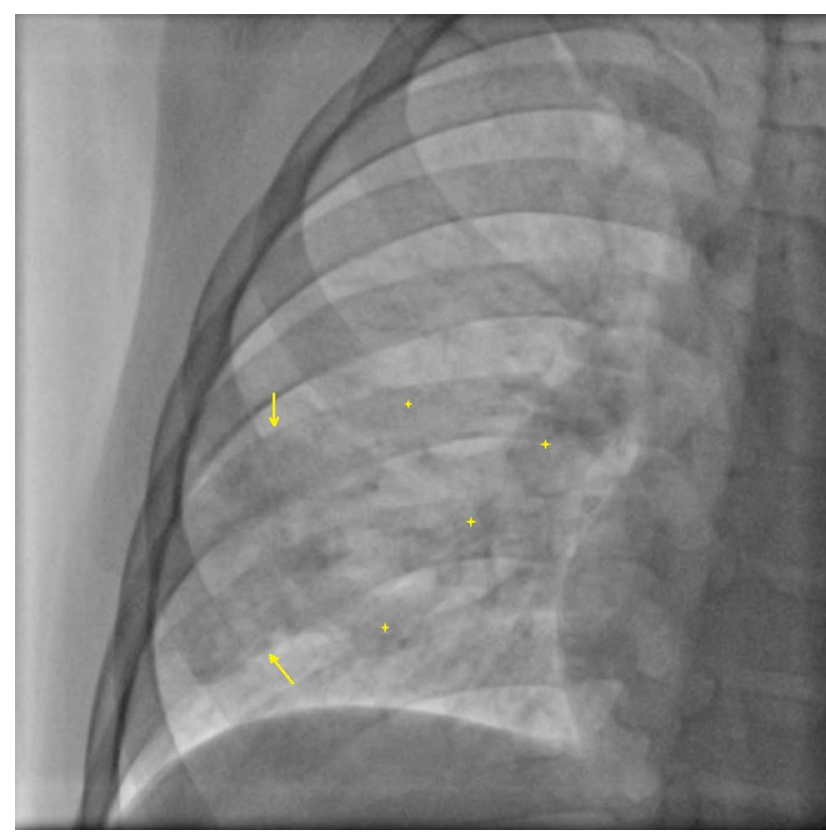

Figure 1: Chest $\mathrm{X}$-ray showed a homogenous opacity in the right lower zone (yellow arrow and stars). after taking written informed consent from his parents and approval from institutional review board regarding the usage of the device. Few of the large AVM had already been closed using Amplatz vascular plug and septal duct occluder at our centre but this was the first one with Cera vascular plug. 6F venous sheath was exchanged with $9 \mathrm{~F}$ sheath. $6 \mathrm{~F} \mathrm{MP}$ catheter was parked into RPA over 0.35 inch Terumo wire (Terumo, Japan). Wire was exchanged with another super-stiff and long $(0.035 ", 260 \mathrm{~cm})$ terumo wire. Keeping wire into lower RPA, multipurpose catheter was exchanged with $9 \mathrm{~F}$ Cook delivery sheath (Cook Medical, USA). After repeated de-airing the vascular plug by immersing into saline, it was screwed over the delivery cable by clockwise rotation. It is recommended that a device is chosen that is at least $30-50 \%$ larger than the size of the native vessel. Therefore, $12 \mathrm{~mm}$ Cera vascular plug (Figure 3) was introduced through sheath using a loader and deployed in lower division of RPA by unscrewing it in counter-clockwise direction (Figure 4). Repeat angiogram was done to check position of first plug and to assess landing zone of second plug (Figure 5A). Another $12 \mathrm{~mm}$ vascular plug was positioned (Figure 5B) and deployed in similar fashion adjacent to first one to occlude the remaining feeder (Figure 6A). Angiogram, obtained after $10 \mathrm{~min}$ of deployment, demonstrated complete closure feeders of both AVMs and perfectly placed plugs (Figure 6B). His oxygen saturation $\left(\mathrm{SpO}_{2}\right)$ improved to $98 \%$, thereby reversing the cyanosis on catheterization table. On follow up at 9 months, clubbing had disappeared (Figure 7).

\section{Discussion}

Right-to-left shunt due to pulmonary arteriovenous malformation is usually well tolerated. Dyspnoea is the most common symptom and clinical presentation depends on the number and size of PAVM. The most

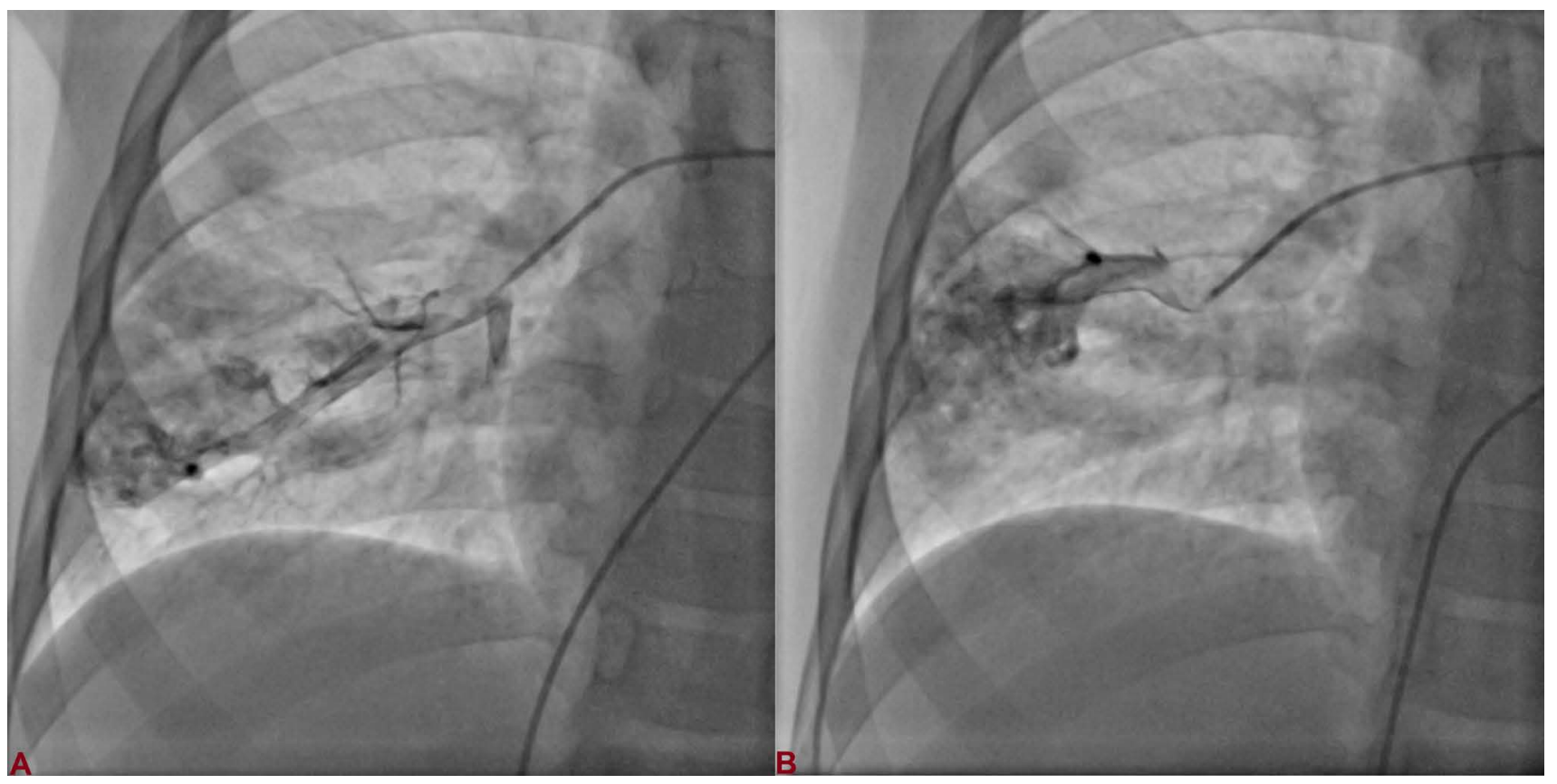

Figure 2: Cardiac catheterization revealed two arteriovenous fistulas arising from right pulmonary artery. 


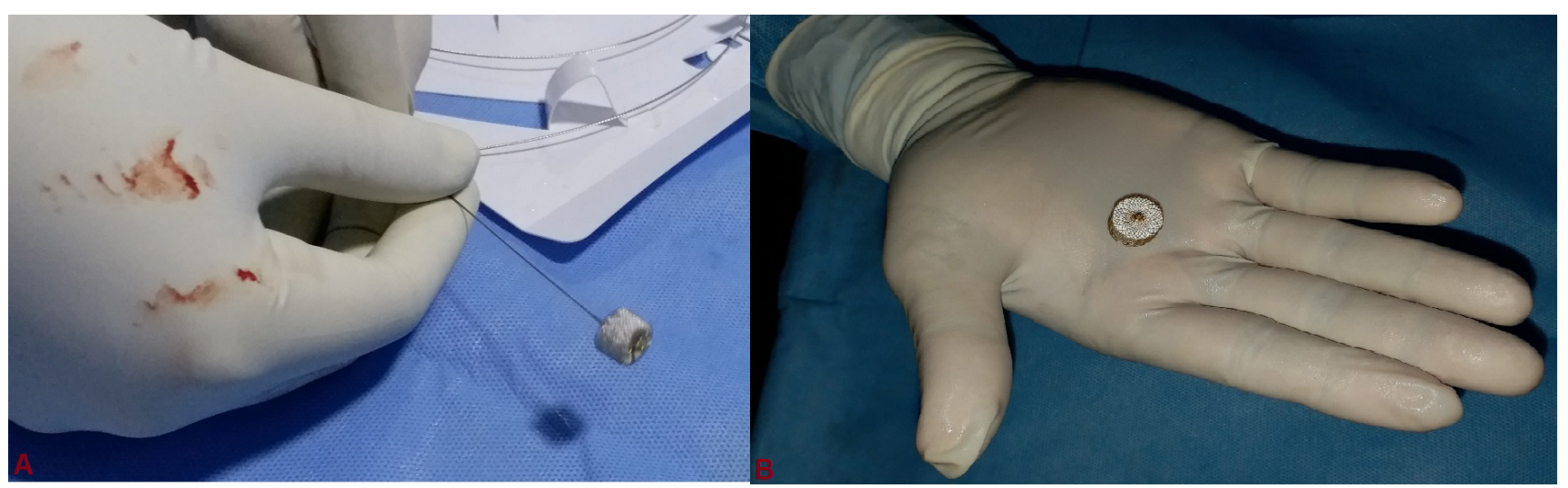

Figure 3: Cera vascular plug with delivery cable.

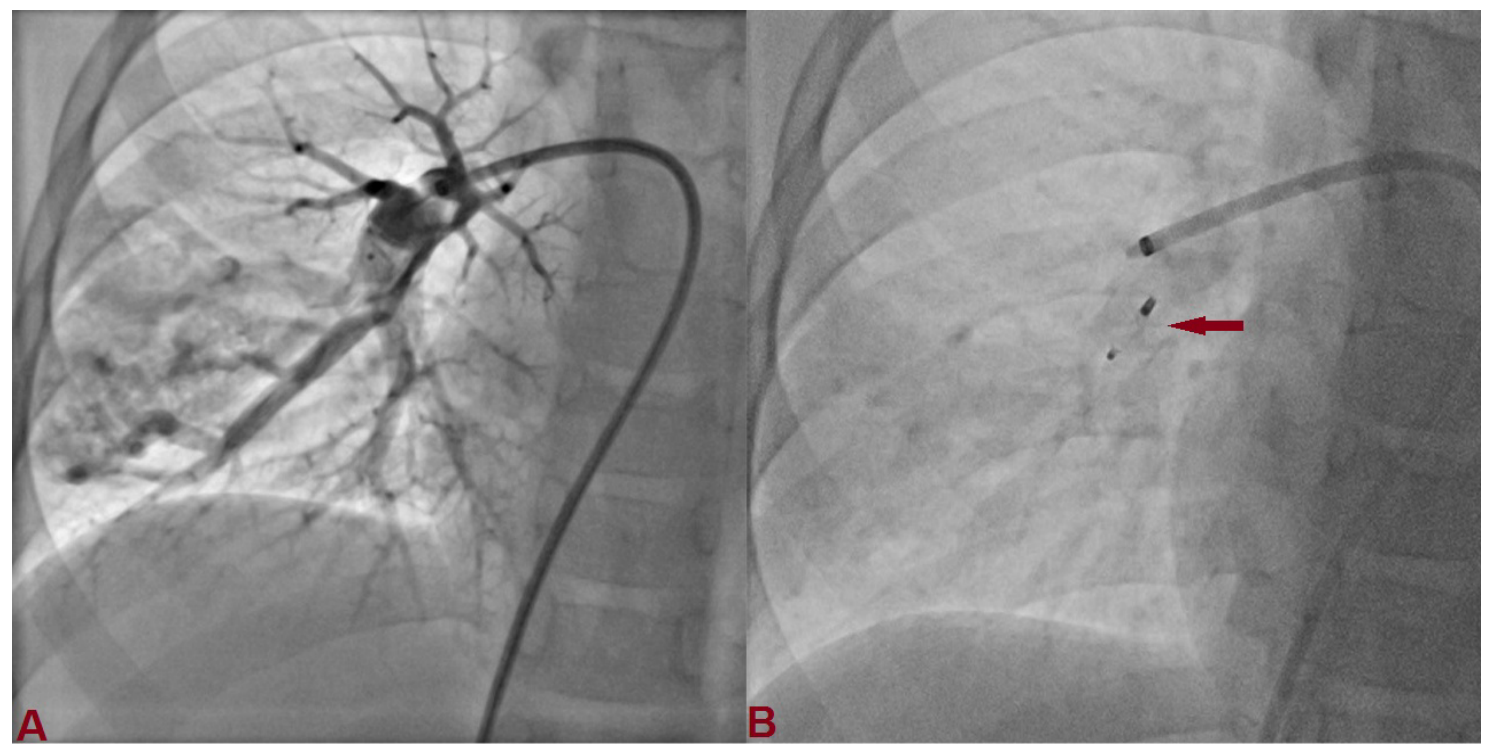

Figure 4: A) A $12 \mathrm{~mm}$ vascular plug was introduced through the sheath and positioned in the lower division of RPA; B) Deployed by unscrewing in counter-clockwise rotation.

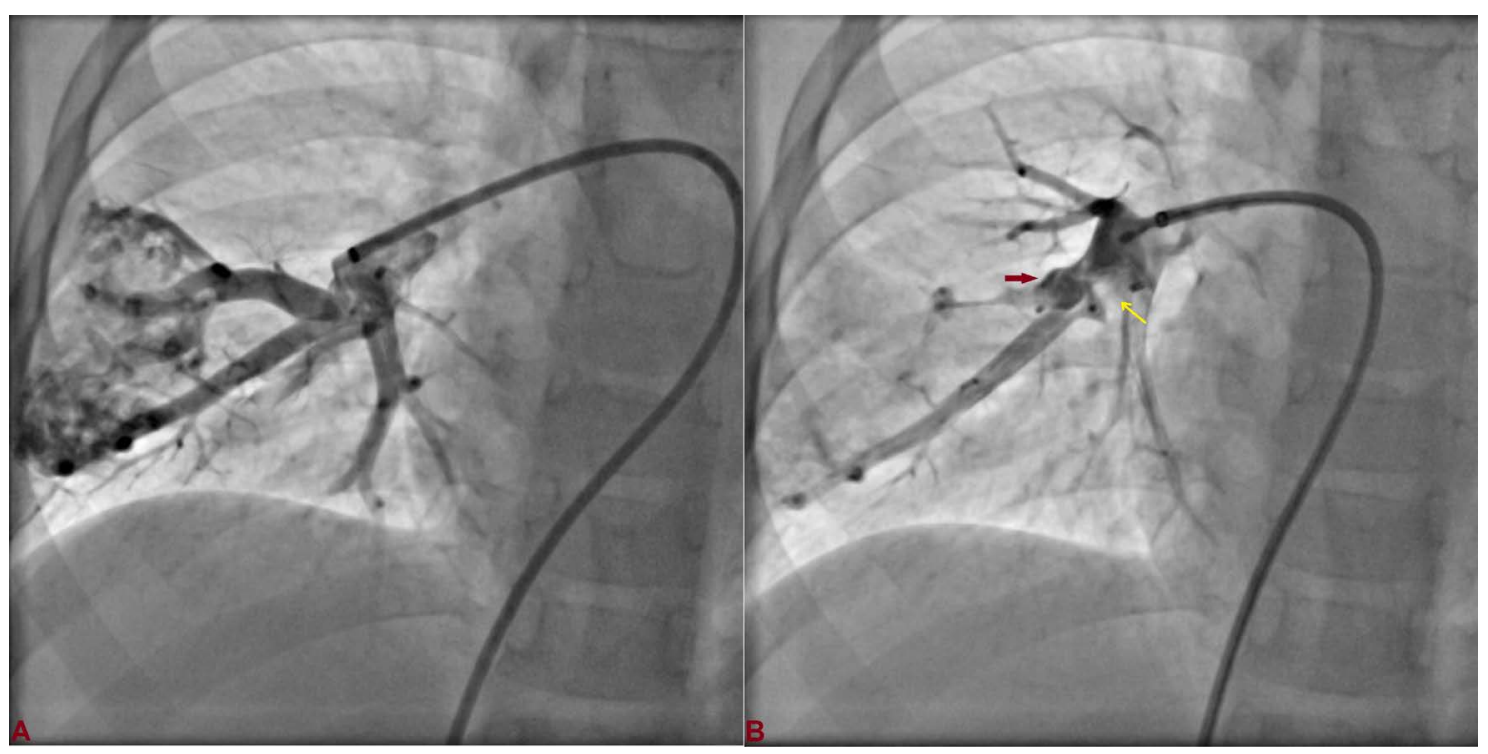

Figure 5: A) Repeat angiogram showing neck of second AVM; B) The second plug (red arrow) was positioned adjacent to first plug (yellow arrow). 


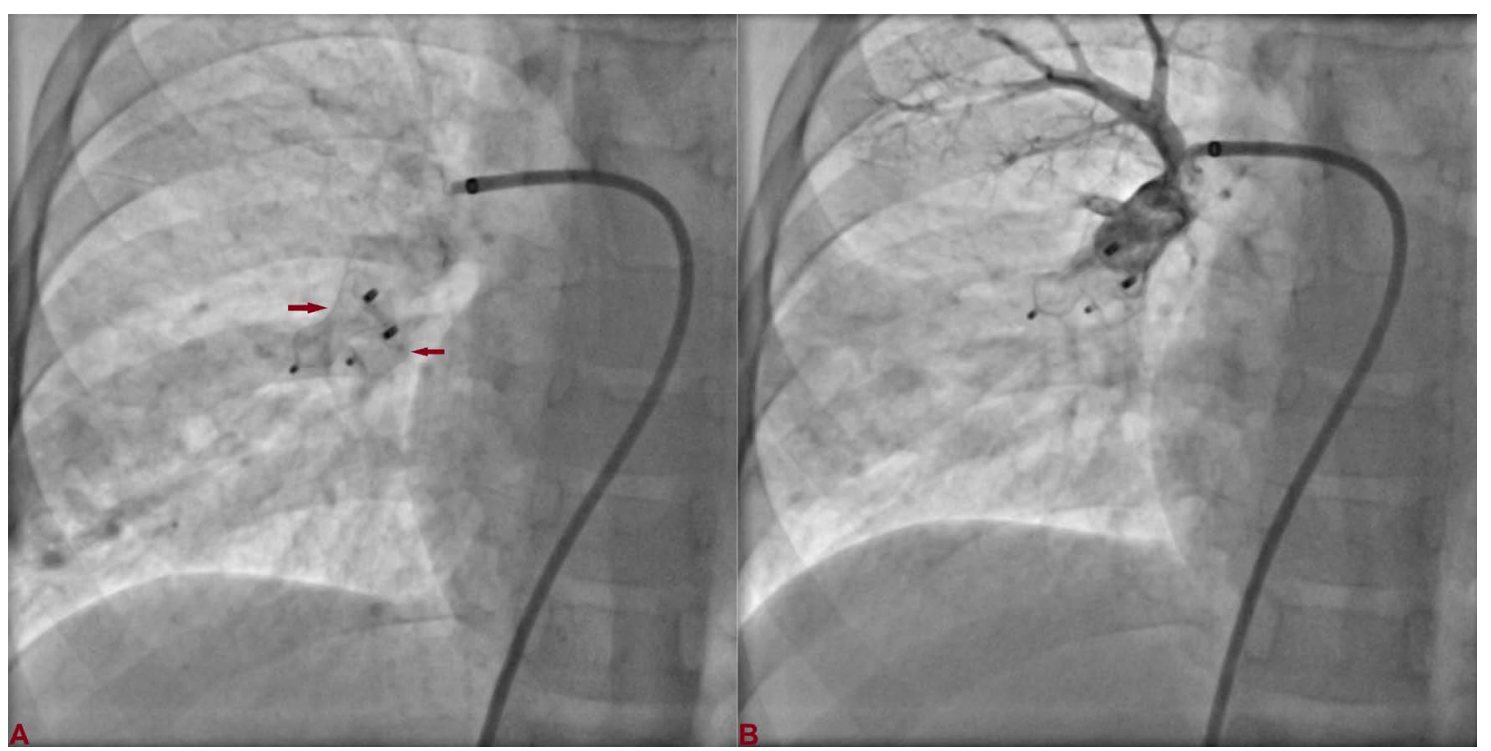

Figure 6: A) Second plug was deployed; B) Final angiogram, obtained after 10 min of deployment, demonstrated complete occlusion of both AVM and perfectly placed plugs.

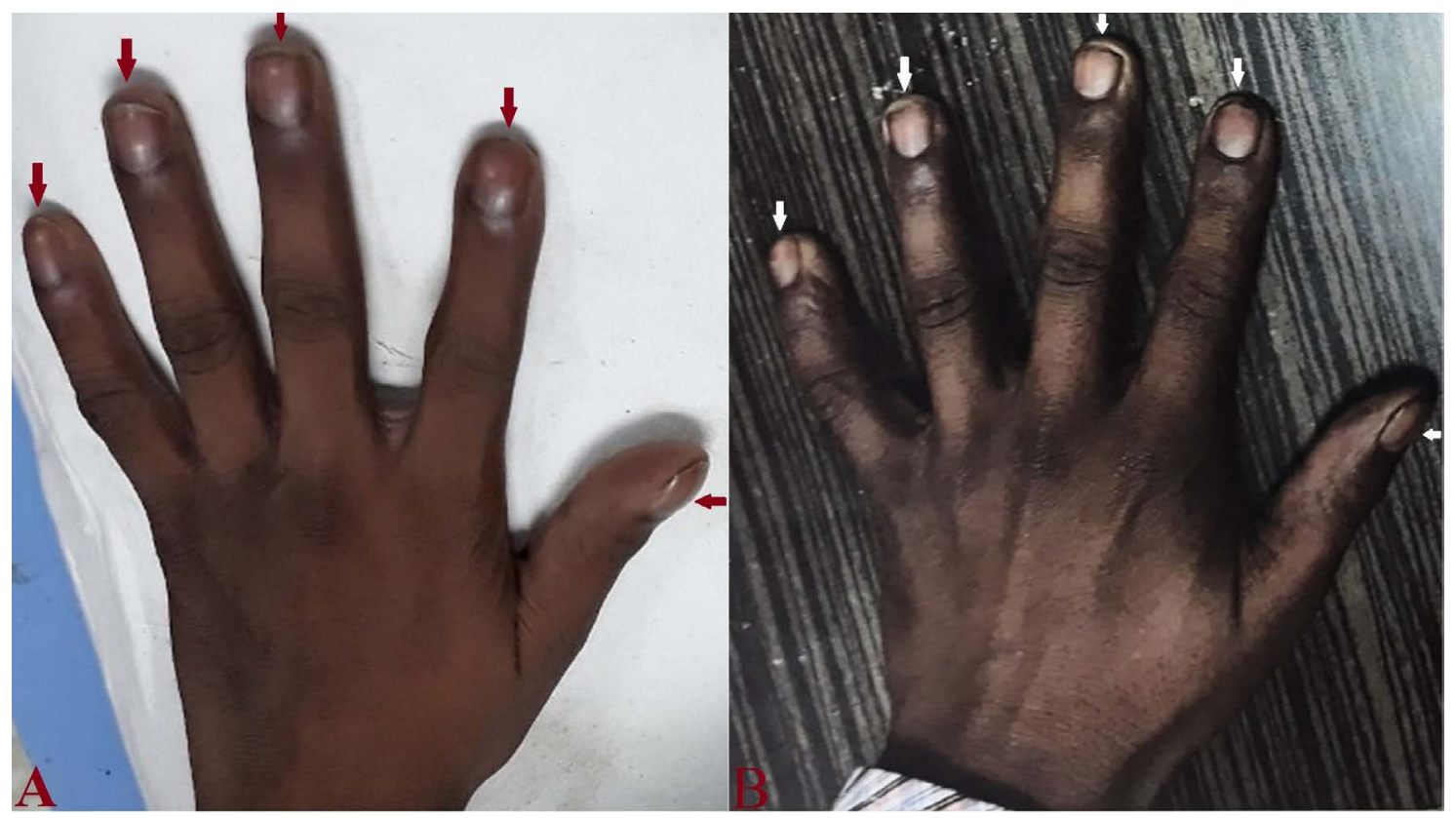

Figure 7: A) Clubbing of fingers (red arrow) in right hand on presentation; B) Complete reversal of clubbing at follow up at 9-months.

sinister sequlae are paradoxical embolism and cerebral abscess due to unobstructed passage of bacteria and thrombi through the AVM [5]. The plug size is decided according to the narrowest diameter of neck, vessel length and landing zone [6]. Vascular plugs are ideally suited to embolized vessels with high flow, which can be achieved using single plug which would otherwise have required multiple coils, thus making it efficient and cost-effective. It also cuts down procedure time, cost, and radiation exposure.

Cera $^{\mathrm{TM}}$ vascular plug is a new device manufactured by Lifetech (Lifetech Scientific Corp., China). It is a self-expandable cylindrical nitinol wire-mesh occlusion device with ceramic coating $[4,8]$. Titanium Nitride coating prevents thrombosis and improves endothelialisation. It has a single lobe and multi-layered nitinol mesh makes the plug faster to occlude [9]. It has a lower recanalization rates and negligible risk of device embolization. Micro screw connection helps in its easy and precise placement. The delivery wire in the vascular plug is more flexible, which makes delivery easier and safer [9]. Accurate placement even in large high flowing vascular structures can be readily achieved with Cera vascular plug compared to coils [9]. The size and the shape of the vascular plug provide radial strength and stable adhesion to the vessel wall and over sizing of the plug also contributes toward preventing migration after deployment [10].

\section{Conflict of Interest}

None. 


\section{Funding}

None.

\section{Statement of Equal Authors' Contribution}

All authors made equal contribution.

\section{References}

1. Cottin V, Plauchu H, Bayle JY, Barthelet M, Revel D, et al (2004) Pulmonary arteriovenous malformations in patients with hereditary hemorrhagic telangiectasia. Am J Respir Crit CareMed 169: 994-1000.

2. White RI Jr, Pollak JS, Wirth JA (1996) Pulmonary arteriovenous malformations: Diagnosis and transcatheter embolotherapy. J Vasc Interv Radiol 7: 787-804.

3. Beck A, Dagan T, Matitiau A, Bruckheimer E (2006) Transcatheter closure of pulmonary arteriovenous malformations with amplatzer devices. Catheter Cardiovasc Interv 67: 932-937.

4. Ferro C, Rossi UG, Bovio G, Seitun S, Rossi GA (2007) Percutaneous transcatheter embolization of a large pulmonary arteriovenous fistula with an amplatzer vascular plug. Cardiovasc Intervent Radiol 30: 328-331.
5. Peirone AR, Spillman A, Pedra C (2006) Successful occlusion of multiple pulmonary arteriovenous fistulae using amplatzer vascular plugs. J Invasive Cardiol 18: E121-E123.

6. Andersen PE, Kjeldsen AD (2007) Occlusion of pulmonary arteriovenous malformations by use of vascular plug. Acta Radiol 48: 496-499.

7. Pollak JS, Saluja S, Thabet A, Henderson KJ, Denbow N, et al. (2006) Clinical and anatomic outcomes after embolotherapy of pulmonary arteriovenous malformations. J Vasc Interv Radiol 17: 35-44.

8. Fiszer R, Szkutnik M, Chodor B, Bialkowski J (2014) Preliminary experience in the use of CERA occluders for closure of different intracardiac and extracardiac shunts. J Invasive Cardiol 26: 385-388.

9. Ramakrishnan S (2015) Vascular plugs - A key companion to Interventionists - 'Just Plug it'. Indian Heart J 67: 399405.

10. Hill SL, Hijazi ZM, Hellenbrand WE, Cheatham JP (2006) Evaluation of the amplatzer vascular plug for embolization of peripheral vascular malformations associated with congenital heart disease. Catheter Cardiovasc Interv 67: 113119. 